\title{
Regulation of immune system cell functions by protein kinase C
}

\section{Noah Isakov ${ }^{1 *}$ and Amnon Altman ${ }^{2}$}

\author{
Faculty of Health Sciences, The Shraga Segal Department of Microbiology, Immunology and Genetics, Cancer Research Center, Ben Gurion University of the \\ Negev, Beer Sheva, Israel \\ 2 Division of Cell Biology, La Jolla Institute for Allergy and Immunology, La Jolla, CA, USA \\ ${ }^{*}$ Correspondence: noah@bgu.ac.il \\ Edited by: \\ Ellis L. Reinherz, Dana-Farber Cancer Institute, USA
}

Keywords: protein kinase $\mathrm{C}, \mathrm{T}$ cell activation, signal transduction pathways, lymphocyte stimulation, cell growth regulation

Cellular responses to environmental cues are mediated through complex networks of signal transduction pathways. Among the molecules involved in these pathways, members of the protein kinase C (PKC) family stand out because of their ability to acutely and reversibly modulate effector protein functions and control the spatial distribution and dynamic properties of the signals. PKC enzymes also contribute to signaling networks that coordinate many aspects of immune cell function and, therefore, are important players in immune regulation.

Originally discovered in 1977, by Nishizuka and coworkers, PKC was initially identified as a cyclic nucleotide-independent protein kinase that is capable of phosphorylating histone and protamine following $\mathrm{Ca}^{2+}$-dependent limited proteolysis of its proenzyme precursor $(1,2)$. Subsequently, Nishizuka demonstrated that activation of PKC can occur in the absence of limited proteolysis by a membrane-associated factor and low $\mathrm{Ca}^{2+}$ concentration (3). He then characterized the membrane-associated factor as diacylglycerol, which is generated by receptor-stimulated hydrolysis of phosphoinositides, suggesting that this lipid functions as a second messenger (4). These findings and additional data established a new pathway of signal transduction and led to identification of biological roles for PKC in signaling pathways linked to a variety of surface receptors in many different cell types.

The PKC family of serine/threonine kinases consists of 10 distinct isoforms that are differentially expressed in a wide range of cell types and tissues. Despite having a certain degree of redundancy and overlapping substrate specificities, individual PKC isoforms also exhibit non-redundant functions. In addition, activity of distinct isoforms can be deployed in a spatially and temporally dependent manner since most isoforms possess a structurally and differentially activated unique regulatory domain. The activity of PKC can therefore be induced by a large variety of agonists and directed by multiple inputs, including second messengers and a variety of PKC-binding proteins.

This Research Topic focuses on recent developments relevant to the role of PKC in immune cell functions, and includes contributions by many of the leading experts in the field. The first paper by Pfeifhofer-Obermair and colleagues (5) reviews current information related to the physiological role and nonredundant functions of different PKC isoforms in T lymphocytes. The authors emphasize the positive contributions of PKCO (6) and $\mathrm{PKC} \alpha(7)$ to antigen-induced $\mathrm{T}$ cell activation and argue that inhibition T cell-mediated responses, including allograft rejection and autoimmunity, requires the inhibition of both PKC isoforms.

Black and Black (8) discuss mechanisms of regulation of $\mathrm{T}$ cell proliferation and cell cycle progression that are mediated by distinct $\mathrm{PKC}$ isoforms and emphasize their predominant role during the G0/G1 and G2 phases. Although PKC was found to modulate an array of cell cycle regulatory molecules, evidence points to $\mathrm{Cdk}$ kinase inhibitors and D-type cyclins as the key mediators of PKCregulated cell cycle-specific effects. The authors indicate that most PKC isoforms play positive roles during cell cycle progression, except for $\mathrm{PKC} \delta$, which serves as a negative regulator.

Another important cellular function that involves $\mathrm{PKC}$ is the establishment and maintenance of cell polarity. This mechanism enables, among other things, the formation of a functional immunological synapse (IS) at the T cell-antigen presenting cell (APC) contact area, and the directional release of cytokines and cytolytic factors from cytotoxic T cells toward their specific target cells. The microtubule organizing complex (MTOC) plays an important role in directing this polarity, and the review by $\mathrm{M}$. Huse covers the process through which PKC family members regulate the formation of the MTOC and its link to the T cell IS (9).

The PKC $\theta$ isoform, which is selectively enriched in T cells (10), is a key modulator of T cell receptor (TCR) signaling and an essential regulator of $\mathrm{T}$ cell activation and survival (11). In antigen-stimulated $\mathrm{T}$ cells, $\mathrm{PKC} \theta$ selectively translocates to the center of the IS, where it mediates critical TCR and CD28 signals leading to the activation of NF- $\kappa \mathrm{B}, \mathrm{AP}-1$ and NFAT transcription factors (12).

A review by Wang and coworkers (13) discusses a major mechanism that regulates $\mathrm{PKC} \theta$, and is also shared by other kinases. This mechanism involves a post-translational process whereby distinct serine, threonine, and tyrosine residues of PKC $\theta$ are autophosphorylated or transphosphorylated, thereby regulating its catalytic activity, as well as its localization within cells and the ability to interact with specific binding partners. The authors focus on the actual PKC $\theta$ phosphorylation sites and their potential role in determining PKC $\theta$ functions. A short comment on this topic is presented by Freeley and Long (14).

Another manuscript, by Isakov and Altman (15), focuses on the molecular mechanism that regulates the translocation of $\mathrm{PKC} \theta$ to 
the center of the IS. This mechanism was discovered only recently by showing that a proline-rich region within the unique V3 (hinge) domain of PKC $\theta$ recruits the enzyme to the cytoplasmic tail of CD28 in a TCR activation-dependent manner (16). The PKC $\theta$ CD28 interaction is mediated via an indirect mechanism involving the Lck protein tyrosine kinase as an intermediate. The authors review progress made in recent years in our understanding of the PKC $\theta$-mediated signal delivery from the TCR/CD28 surface receptors.

Another facet of PKC $\theta$ relates to its nuclear function in T cells, where it was found to associate with chromatin in a cell activationdependent manner. PKC $\theta$ interacts with selected nuclear proteins with which it forms active complexes that associate with proximal promoters of inducible T cell genes, including CD69, INF- $\gamma$, and TNF- $\alpha$ (17). The nuclear function of PKC $\theta$ and its potential involvement in specific transcriptional programs in $\mathrm{T}$ cells are discussed by Sutcliffe and colleagues (18).

In addition to the TCR, additional receptors, including OX40, a member of the tumor necrosis factor receptor (TNFR) superfamily, also utilize PKC $\theta$ for signal transmission, a topic that is presented in this issue by So and Croft (19). Following activation of T cell-expressed OX40 by its APC-expressed ligand, OX40L, activated OX40 delivers TCR-independent signals that promote optimal activation of NF- $\kappa \mathrm{B}$, using signaling intermediates that are distinct from those utilized by the TCR, e.g., TRAF proteins and RIP1.

PKC $\theta$-deficient mice serve as an important tool for deciphering underlying mechanisms in cellular immune responses. While in vitro studies of PKC $\theta$-deficient $\mathrm{T}$ cells demonstrated impaired activation responses, in vivo studies indicated that the requirement for PKC $\theta$ is not universal. Anel and colleagues (20) discuss the involvement of PKC $\theta$ in natural killer cell function and anti-tumor immunity, while the importance of PKC $\theta$ during the induction of graft-versus-host and graft-versus-leukemia responses, or in antiviral immunity is reviewed by Bronk and colleagues (21).

In another review, Sun (22) elaborates on the potential role of PKC $\theta$ in maintaining the normal balance between effector and regulatory $\mathrm{T}$ cells and the possibility of targeting $\mathrm{PKC} \theta$ for intervention in $\mathrm{T}$ cell responses and prevention of selected autoimmune diseases and allograft rejection.

Both PKC $\eta$ and PKC $\theta$ are members of the novel PKC subfamily that are highly expressed in T cells. However, in contrast to $\mathrm{PKC} \theta$, which is concentrated at the center of the IS in activated T cells, $\mathrm{PKC \eta}$ remains localized in a diffuse pattern over the entire IS, suggesting distinctive roles for these two isoforms in signal relay downstream of the TCR. Fu and Gascoigne (23) discuss the specific roles of PKC $\eta$ and its functional redundancy with $\mathrm{PKC} \theta$ in $\mathrm{T}$ cell biology.

Members of the atypical PKC subfamily (aPKC), including $\mathrm{PKC} \zeta$ and $\mathrm{PKCl} / \lambda$, are also expressed in lymphocytes and play important roles in $\mathrm{T}$ and $\mathrm{B}$ cell differentiation, as well as in the regulation of $\mathrm{T}$ cell polarization and survival. A detailed description of the mechanism of action of aPKCs, in conjunction with their adapters, p62 and Par-6, in the PB-1-orchestrated signaling network that regulates lymphocyte behavior, is provide by Martin and Moscat (24).

\section{ACKNOWLEDGMENTS}

We would like to thank all these authors for their valuable contribution to this Research Topic, and the referees for their valuable suggestions and critical comments. We hope our readers will find the articles in this Research Topic informative, timely, and enlightening.

\section{REFERENCES}

1. Inoue M, Kishimoto A, Takai Y, Nishizuka Y. Studies on a cyclic nucleotideindependent protein kinase and its proenzyme in mammalian tissues. II. Proenzyme and its activation by calcium-dependent protease from rat brain. J Biol Chem (1977) 252:7610-6.

2. Takai Y, Kishimoto A, Inoue M, Nishizuka Y. Studies on a cyclic nucleotideindependent protein kinase and its proenzyme in mammalian tissues. I. Purification and characterization of an active enzyme from bovine cerebellum. J Biol Chem (1977) 252:7603-9.

3. Takai Y, Kishimoto A, Iwasa Y, Kawahara Y, Mori T, Nishizuka Y. Calciumdependent activation of a multifunctional protein kinase by membrane phospholipids. J Biol Chem (1979) 254:3692-5.

4. Kishimoto A, Takai Y, Mori T, Kikkawa U, Nishizuka Y. Activation of calcium and phospholipid-dependent protein kinase by diacylglycerol, its possible relation to phosphatidylinositol turnover. J Biol Chem (1980) 255:2273-6.

5. Pfeifhofer-Obermair C, Thuille N, Baier G. Involvement of distinct PKC gene products in T cell functions. Front Immunol (2012) 3:220. doi:10.3389/fimmu. 2012.00220

6. Baier G, Telford D, Giampa L, Coggeshall KM, Baier-Bitterlich G, Isakov N, et al. Molecular cloning and characterization of PKC theta, a novel member of the protein kinase $\mathrm{C}$ (PKC) gene family expressed predominantly in hematopoietic cells. J Biol Chem (1993) 268:4997-5004.

7. Pfeifhofer C, Gruber T, Letschka T, Thuille N, Lutz-Nicoladoni C, HermannKleiter N, et al. Defective IgG2a/2b class switching in PKC alpha-/- mice. J Immunol (2006) 176:6004-11.

8. Black AR, Black JD. Protein kinase C signaling and cell cycle regulation. Front Immunol (2012) 3:423. doi:10.3389/fimmu.2012.00423

9. Huse M. Microtubule-organizing center polarity and the immunological synapse: protein kinase C and beyond. Front Immunol (2012) 3:235. doi:10. 3389/fimmu.2012.00235

10. Meller N, Elitzur Y, Isakov N. Protein kinase C-theta distribution analysis in hematopoietic cells: proliferating $\mathrm{T}$ cells exhibit high proportions of $\mathrm{PKC}$-theta in the particulate fraction. Cell Immunol (1999) 193:185-93. doi:10.1006/cimm. 1999.1478

11. Isakov N, Altman A. Protein kinase C-theta in T cell activation. Annu Rev Immunol (2002) 20:761-94. doi:10.1146/annurev.immunol.20.100301.064807

12. Baier-Bitterlich G, Uberall F, Bauer B, Fresser F, Wachter H, Grunicke H, et al. Protein kinase C-theta isoenzyme selective stimulation of the transcription factor complex AP-1 in T lymphocytes. Mol Cell Biol (1996) 16:1842-50.

13. Wang X, Chuang HC, Li JP, Tan TH. Regulation of PKC-theta function by phosphorylation in T cell receptor signaling. Front Immunol (2012) 3:197. doi:10.3389/fimmu.2012.00197

14. Freeley M, Long A. Regulating the regulator: phosphorylation of PKC theta in T Cells. Front Immunol (2012) 3:227. doi:10.3389/fimmu.2012.00227

15. Isakov N, Altman A. PKC-theta-mediated signal delivery from the TCR/CD28 surface receptors. Front Immunol (2012) 3:273. doi:10.3389/fimmu.2012.00273

16. Kong KF, Yokosuka T, Canonigo-Balancio AJ, Isakov N, Saito T, Altman A. A novel motif in the $\mathrm{V} 3$ domain of protein kinase $\mathrm{C}$-theta (PKC-theta) determines its immunological synapse localization and functions in $\mathrm{T}$ cells via association with CD28. Nat Immunol (2011) 12:1105-12. doi:10.1038/ni.2120

17. Sutcliffe EL, Bunting KL, He YQ, Li J, Phetsouphanh C, Seddiki N, et al. Chromatin-associated protein kinase $\mathrm{C}$-theta regulates an inducible gene expression program and microRNAs in human T lymphocytes. Mol Cell (2011) 41:704-19. doi:10.1016/j.molcel.2011.02.030

18. Sutcliffe EL, Li J, Zafar A, Hardy K, Ghildyal R, McCuaig R, et al. Chromatinized protein kinase C-theta: can it escape the clutches of NF-kappaB? Front Immunol (2012) 3:260. doi:10.3389/fimmu.2012.00260

19. So T, Croft M. Regulation of the PKCtheta-NF-kappaB axis in T lymphocytes by the tumor necrosis factor receptor family member OX40. Front Immunol (2012) 3:133. doi:10.3389/fimmu.2012.00133 
20. Anel A, Aguilo JI, Catalan E, Garaude J, Rathore MG, Pardo J, et al. Protein kinase C-theta (PKC-theta) in natural killer cell function and anti-tumor immunity. Front Immunol (2012) 3:187. doi:10.3389/fimmu.2012.00187

21. Bronk CC, Yu XZ, Beg AA. Targeting PKC theta in alloreactivity and graft-versushost-disease: unanswered questions and therapeutic potential. Front Immunol (2012) 3:259. doi:10.3389/fimmu.2012.00259

22. Sun Z. Intervention of PKC-theta as an immunosuppressive regimen. Front Immunol (2012) 3:225. doi:10.3389/fimmu.2012.00225

23. Fu G, Gascoigne NR. The role of protein kinase ceta in T cell biology. Front Immunol (2012) 3:177. doi:10.3389/fimmu.2012.00177

24. Martin P, Moscat J. Th1/Th2 differentiation and B cell function by the atypical PKCs and their regulators. Front Immunol (2012) 3:241. doi:10.3389/fimmu. 2012.00241
Received:07 October 2013; accepted: 04 November 2013; published online: 18 November 2013.

Citation: Isakov N and Altman A (2013) Regulation of immune system cell functions by protein kinase C. Front. Immunol. 4:384. doi: 10.3389/fimmu.2013.00384

This article was submitted to T Cell Biology, a section of the journal Frontiers in Immunology.

Copyright (c) 2013 Isakov and Altman. This is an open-access article distributed under the terms of the Creative Commons Attribution License (CC BY). The use, distribution or reproduction in other forums is permitted, provided the original author(s) or licensor are credited and that the original publication in this journal is cited, in accordance with accepted academic practice. No use, distribution or reproduction is permitted which does not comply with these terms. 